\title{
Impacts of Global Pandemic Outbreak of Novel Coronavirus on Massive Humanity: A Data Analysis
}

\author{
Md. Amir Hossain
}

PhD (Research Scholar) in English literature, Jahangirnagar University, Bangladesh

DOI: $10.36347 /$ sjmcr.2020.v08i05.025

| Received: 25.04.2020 | Accepted: 07.05.2020 | Published: 27.05.2020

*Corresponding author: Md. Amir Hossain

Abstract

Case Report

The aim of this research project is to investigate the impacts of pandemic outbreak of fatal coronavirus on massive humanity. Its aim is to look at the terrifyingly difficult situation of global population. It would like to focus on origination, history, outbreak, reaction of new coronavirus which was primarily found in Wuhan city in China. Based on medical science, symptoms and diagnosis are critically analyzed to show a practical image of COVID-19 in this study. How coronavirus breaks lineage out in human body; how it damages lungs and alveoli seriously; and how shortage of oxygen occurs throughout the body has been discussed here apparently. Data have been collected from global daily newspapers, doctors, health specialists, and reporters, internet sources, the global news, World meters, World Health Organization, United Nations, United Nations Office for the Coordination of Humanitarian Affairs, BBC News, CNN News, BTV News, and NPR News with a view to showing the prevalent impacts of new coronavirus on the massive humanity. Data have been analyzed to expose the number of infection, death and recovery based on the reports of WHO and Worldometers as of 16 April 2020. Novel coronavirus (2019-nCOV) preventive measures have been discussed to make the people conscious of coronavirus. Quarantine, home quarantine, lockdown and social distancing have been given priority in this research.

Keywords: COVID-19 Novel Coronavirus, Pandemic Outbreak, WHO, UN, and Massive Humanity.

Copyright @ 2020: This is an open-access article distributed under the terms of the Creative Commons Attribution license which permits unrestricted use, distribution, and reproduction in any medium for non-commercial use (NonCommercial, or CC-BY-NC) provided the original author and source are credited.

\section{INTRODUCTION}

According to World Health Organization, coronaviruses consist of a large family of viruses which cause illness between man and animal. Several coronaviruses cause respiratory infections ranging from common cold to more severe diseases, like Middle East Respiratory Syndrome (MERS) and Severe Acute Respiratory Syndrome (SARS). The very recently discovered coronavirus causes coronavirus disease COVID-19. It is an infectious disease caused by coronavirus. This novel virus and disease were not known to us before the pandemic outbreak commenced in Wuhan, China, in December 2019.

The common symptoms of COVID-19 are fever, tiredness, and dry cough. Some patients may feel aches and pains, nasal congestion, runny nose, sore throat or diarrhea. The mild symptoms are seen slowly. Some people get infected but don't develop any symptoms. About $80 \%$ of people recover from this infectious disease without any special treatment. Around 1 out of every 6 people who gets COVID-19 becomes seriously ill and develops difficulty breathing.
Older people with underlying medical problems, including high blood pressure, heart problem or diabetes, are likely to develop serious illness. People with having fever, cough and difficulty breathing must consult the doctors without making any delay.

People catch COVID-19 from others who have already been infected by coronavirus. The virus spread from person to person through small droplets from the nose or mouth while a man with coronavirus coughs or exhales. These droplets land on objects and surfaces around the man. Other people are also infected by COVID-19 who touch such things or surfaces, then touch their eyes, nose or mouth. They catch COVID-19 if they breathe in droplets from the infected patients who cough out or exhale droplets. Therefore, it is very much important to stay more than 1 meter or 3 feet away from a sick man. At this time, there are no specific vaccines or treatments for COVID-19[1]. However, it is reported that coronavirus was originated in Wuhan city in China from bats, snakes, sea-food, and

1 . https://www.who.int/news-room/q-a-detail/q-acoronaviruses 
other wild beasts. On 27 January 2020, the presence of coronavirus was diagnosed among about 4515 people's body from which 976 people was badly injured.

For this purpose, this paper would like to focus on symptoms and diagnoses of novel coronavirus. Coronavirus causes infections, fever, fatigue, muscle aches, dry cough, shortness of breath, and respiratory diseases, for example bronchitis and pneumonia. Coronavirus breaks lineage out in human body and builds their nest in lung and breeding spreads gradually. The virus begins to spread its lineage out and lung and alveoli get damaged. As a result, the patients feel a shortage of oxygen and become sick very seriously and even fall victim of premature death.

This paper would like to investigate the deadliest impacts of pandemic outbreak of fatal coronavirus on the massive humanity. According to Worldometers, COVID-19 coronavirus pandemic as of 17 April 2020, the total number of infected patients was $2,219,314$ among which 149,900 patients die prematurely and 560,975 people get recovered. The United Nations launches a US\$2 billion coordinated global humanitarian response plan to fight against COVID-19 in the most vulnerable countries for protecting the millions of people.

Data were collected from the information and reports of the daily newspapers, doctors, health specialists, and reporters, internet sources, the Global News, Worldometers, World Health Organization, United Nations, United Nations Office for the Coordination of Humanitarian Affairs, BBC News, CNN News, BTV News, and NPR News with a view to conducting this research project.

This study analyses the total conformed cases, the total number of deaths, and the total number of recovered people of the severely infected countries, like USA, UK, Italy, France, Spain, Germany, Belgium, Netherlands, China, Iran, India, and Bangladesh. It also focuses on the death rate and recovery rate of these countries to find out the real picture of COVID-19 coronavirus pandemic outbreak.

Novel coronavirus (2019-nCOV) preventive measures, including social distancing, isolation, quarantine, home quarantine, lockdown, safety of disintegration process, and so on have been discussed elaborately in this research paper.

\section{Origination and History}

Coronavirus is a Severe Acute Respiratory Syndrome Coronavirus 2 which is known as SARSCoV-2[2]. It is a new type of coronavirus; it is RNA coronavirus. According to World Health Organization, its initial name was 2019-Novel Coronavirus which is

2 . Coronavirus has a name: The Deadly Disease is Covid-19, 11 February, 2020. known as 2019-nCoV [3]. It is also known as Wuhan Coronavirus [4] since it is originated from Wuhan province, China. Regarding the suspicious events of Severe Acute Respiratory Syndrome Coronavirus 2, World Health Organization was informed on 31 December 2019. The Chief of WHO Tedros Adhanom Ghebreyesus informed the journalists of this novel coronavirus in Geneva, Switzerland. He said: "This disease has a name to us. Its name is COVID-19[1]".

Frias [2] points out that Wei Guixian, who was fifty seven years old and a seafood seller in the Huanan market in Wuhan city, was among the first 27 patients to get infected with coronavirus, which originated from the wet market where she worked. Wei first began to exhibit coronavirus symptoms on 10 December 2019; and then, she was hospitalized less than a week later, where doctors described her illness as 'very serious and ruthless', according to The Journal and The New York Post.

In Wuhan market, besides sea-food, rats, snakes, and other wild animals along with their slaughtered bodily organs were sold out. People think that coronavirus spreads out from those wild animals to the domestic animals. As a result, it enters human body; and man is infected by it. Coronavirus is a large body of virus which can infect animal and man. Before the $21^{\text {st }}$ century, coronavirus would not create any fatal disease or symptoms except normal cough, cold, fever, or headache. But, in the current $21^{\text {st }}$-century, there are 3-types of coronavirus, which are created: SARS, MERS, and Wuhan coronavirus. These coronavirus are found to enter human body and infect very fatally [5]. Medical researchers and scientists see $70 \%$ of similarity of genome sequence between Wuhan Coronavirus and SARS Coronavirus. In 2002 in China, SARS-COV infected and spread pandemically and epidemically from the market of same types of wild animals. Then the virus spreads out in 30-countries of the world where 8437 people got infected; and 813 people died [6] Moreover, in 2012, Middle Eastern Respiratory Syndrome-related Coronavirus (MERS-COV) spreads out from Saudi Arabia, this fatal and deadly coronavirus infected human body originating from camels' body. It then spread out in 27-countriues. Consequently, 2494

3 . "Novel coronavirus (2019-nCoV), Wuhan, China" / cdc.gov / cdc.gov. / 10 January 2020.

4 . Zhang, Y.-Z. (12 January 2020). "Wuhan seafood market pneumonia virus isolate Wuhan-Hu-1, complete genome," Gen Bank, Bethesda MD.

5 . Sparrow, Anni. "How China's Coronavirus Is Spreading - and How to Stop It." www.foreignpolicy.com

6 . "China battles coronavirus outbreak: All the latest updates." www.aljazeera.com 
people got infected; and 858 people died prematurely [7].

According to the public opinion, SARS-COV2 or 2019-nCOV was diagnosed for the first time in Wuhan in China in December 2019. Coronavirus began to break out other provinces of China and also other countries of the world, like Thailand, Japan, Taiwan, South Korea, Australia, France, United States of America [8] and beyond gradually. On 27 January 2020, it was informed that 4585 people were infected due to coronavirus; among them 4519 people were Chinese[9]. Still now the occurrences are getting happened beyond China; the reason is that infected events are connected to China, i.e. the infected persons have travelled in Wuhan who are straightly connected to China [10]. On 27 January 2020, 109 people died [11]; and Chinese researchers of Guangdong province point out that the reason of outbreak of coronavirus disease is that this virus spreads from one human body to another [12]. The virus is transmitted from man to another through droplets or contact.

\section{Outbreak in Wuhan}

According to medical scientists, Wuhan Coronavirus-19 is comparatively large in size. Its size is approximately 125 nanometer (a portion of about 1 crore of 1 meter). Because of its large in size, coronavirus cannot float in the air for more than a few hours and even it cannot travel farther than a few feet. Like an influenza virus, it is transmitted from one man to another through contact. At the time of close contact between friends and family members, this virus can be infected straightly from one person to another through sneezing, coughing, saliva, and spit coming from the mouth. On the other hand, if any infected person coughs or crouches with having a virus in public places and gatherings, the virus can be found on nearby surfaces, like a door handle, a bed or a cellphone, and can spread

7 . "China battles coronavirus outbreak: All the latest updates." www.aljazeera.com

8 . "China coronavirus: Hong Kong widens criteria for suspected cases after second patient confirmed, as MTR cancels Wuhan train ticket sales", Hong Kong: South China Morning Post, 23 January 2020; European Centre for Disease Prevention and Control. (25 January 2020). "Novel coronavirus: three cases reported in France", Doherty, Ben. (25 January 2020). "Coronavirus: three cases in NSW and one in Victoria as infection reaches Australia", The Guardian.

9. "Operations Dashboard for ArcGIS", gisanddata.maps.arcgis.com, 27 January 2020.

10 . "Novel Coronavirus (2019-nCoV)", Situation Report-5, 25 January 2020.

11 . "Operations Dashboard for ArcGIS", gisanddata.maps.arcgis.com, 27 January 2020.

${ }^{12}$ Canadian Broadcasting Corporation (20 January 2020). "China confirms human-to-human transmission of new coronavirus." it to another person indirectly. Besides, at the time of treatment of a coronavirus infected person, like clommonavirus or respiratory tract, the floating particles in the air can infect co-physicians in the hospital. If any precautionary steps cannot be taken, this virus can break out in a hospital very swiftly. It can be feasible to decrease the outbreak of virus particles floating in the air through washing hand clearly and wearing cloth or gown, gloves, PPE, masks and glasses. Though the incubation period for infection and symptoms of the virus has not been diagnosed yet, it is assumed that the infection will be seen within 1-14 days of the infection [13].

\section{Reactions in Wuhan}

On 27 January 2020, the presence of coronavirus was diagnosed among about 4515 people's body among which 976 people were badly injured [14]. The first man who was infected by coronavirus died on 9 January 2020. 101people died owning to coronavirus till 27 January 2020.

New Year festival was postponed or cancelled in many cities of China with a view to preventing the outbreak of coronavirus. Festival-stimulating public meetings and gatherings were strictly forbidden. Tourist attractions were also closed to the public. Under the Chinese government's direction, all sorts of inbound and outgoing public transport services were suspended in Wuhan and five other cities in Hupei province. Also, all inbound and outgoing public transport services were suspended in another 17 cities in China. As a result, about 5 crore of Chinese people, including 1 crore and 10 lakhs of residents of Wuhan city, lived almost the blocked lives. Special hospitals are being constructed to treat coronavirus infected people in Wuhan.

\section{Symptoms and Diagnosis}

The victims may appear to be healed due to coronavirus; and flu-like symptoms may be seen. These include fever, cough, and less severe respiratory problems.

In the lower cases, some symptoms of the upper respiratory tract, like sneezing, runny nose, and throat pain, etc.[15] gastrointestinal symptoms, including nausea, vomiting, and diarrhea are also seen.

13 .Sparrow, Anni. "How China's Coronavirus is Spreading - and How to Stop It." www.foreignpolicy.com

14 . https://globalnews.ca/news/6470807/chinacoronavirus-death-toll-raises

15. Chen N, Zhou M, Dong X, Qu J, Gong F, Han Y, and Others. (February 2020). "Epidemiological and clinical characteristics of 99 cases of 2019 novel coronavirus pneumonia in Wuhan, China: a descriptive study." $\quad$ Lancet 395 (10223): 507 513, PMID 32007143. 


\begin{tabular}{|l|l|}
\hline \multicolumn{2}{|c|}{ Rate of Symptoms[16] } \\
\hline Symptoms & Rate \\
\hline Fever & $87.9 \%$ \\
\hline Dry Cough & $67.7 \%$ \\
\hline weariness & $38.1 \%$ \\
\hline Spit & $33.4 \%$ \\
\hline $\begin{array}{l}\text { Shortness of } \\
\text { breath }\end{array}$ & 18.6 \\
\hline Muscle Aches & $14.8 \%$ \\
\hline Sore Throat & $13.9 \%$ \\
\hline Headache & $13.6 \%$ \\
\hline Cold Body & $11.4 \%$ \\
\hline Nausea & $5.0 \%$ \\
\hline Nose Closed & $4.8 \%$ \\
\hline Diarrhea & $3.7 \%$ \\
\hline Hemoptysis & $0.9 \%$ \\
\hline Conjunctiva & $0.8 \%$ \\
\hline
\end{tabular}

In some cases in China, heart disease, like chest pain or chest tightness, or palpitations may be the next stage of disorder as pneumonia, multiple organ dysfunction and even death[17]. Like other infections, symptoms are found in the infected person shortly after getting infected. This time is called dormancy. The prevalence of COVID-19 disease usually remains 5-6 days; and again it remains 2-14 days.

Coronavirus causes infections, fever, fatigue, muscle aches, dry cough, shortness of breath, and respiratory diseases, for example bronchitis and pneumonia. Sometimes there may cause cough with headache or cough. Blood test of the patients shows that virus reduces their white blood cell count. Liver as well as kidney are damaged showily. Symptoms do not seem to be as complex as a doctor's consultancy until one week. But, by the second week, the condition of the patient may be deteriorated rapidly and severely. With the increase of lungs, oxygen deficiency (hypoxemia) is seen in the arterial blood; and the patient has to undergo an oxygen treatment. Moreover, Acute Respiratory Distress Syndrome (ARDS) is also observed. 20\%-25\% of patients have to be breathed mechanically in an intensive care unit or ICU; and sometimes oxygen is added to blood through circulation inside the artificial lung. There is a great possibility of a second bacterial pneumonia caused by extensive lung damage [18].

16 . World Health Organization. "Report of the WHOChina Joint Mission on Coronavirus Disease-2019 (COVID-19)."

17. Hui DS, Azhar E, Madani TA, Ntoumi F, Kock R, Dar O. (February 2020). "The continuing 2019-nCoV epidemic threat of novel coronaviruses to global health - The latest 2019 novel coronavirus outbreak in Wuhan, China." International Journal of Infectious Diseases, issue 91, pp264-66.

18 . Sparrow, Anni. "How China's Coronavirus Is Spreading-and How to Stop It." www.foreignpolicy.com
Though influenza virus has symptoms like infection, flu medicine does not work. Still now no medicine or vaccine has been discovered for coronavirus. Without any intensive treatment in the hospital, there is no way to recover from the disease. Immunity becomes low; and as a result, the patient is more likely to die of pneumonia which is especially seen in the lives of the full-aged people $(60+$ yrs.). So far, there has not been seen any possibility of being more deadly than influenza. It can be mentioned here that 4 lakhs of people die of influenza virus every year [19].

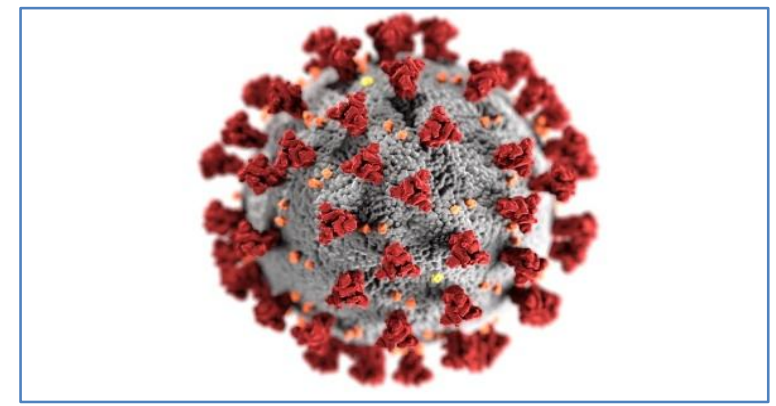

\section{Coronavirus's Lineage in Human Body}

Sayrin Ferdous points out that not only coronavirus but also other viruses neither live a long time nor spread their lineage. Coronavirus builds their nest in lung and breeding spreads out swiftly. Human lung is made of Alveoli [20], like small balls which swell up and down with respiration. These balls are very important for body whose functions are to fill oxygen through supplying the whole body.

Oxygen enters blood when alveoli punctures though thin screen. Then poisonous carbon dioxide comes out from blood. Each cell of human body lives through inhaling oxygen. When coronavirus enters human body, it breaks out in respiratory chord and lung. Then it begins to spread its lineage out. Lung and alveoli get damaged. When the virus enters human body, it takes 5 days to spread out. Symptoms, such as fever, fatigue, muscle aches, dry cough, diarrhea, and shortness of breath are noticed. On the other hand, immune system tries heart and soul to get rid of coronavirus. Human immune system tries to create necessary antibody cell with a view to defeating this virus. If the speed of propagation of immune cell is stronger than that of coronavirus, a man will live. On the other hand, if immune system is weak, the breeding

19. Boseley, Sarah, Hannah Devlin, and Martin Belam. (28 January 2020). "What is coronavirus and how worried should we be?" The Guardian.

${ }^{20}$.Alveoli are an important part of the respiratory system whose function it is to exchange oxygen and carbon dioxide molecules to and from the bloodstream. These tiny, balloon-shaped air sacs sit at the very end of the respiratory tree and are arranged in clusters throughout the lungs. 
of virus will break out in lung swiftly. At one time human body will feel a shortage of oxygen. As a result, other bodily organs, like kidney, heart, liver begin to get weakened. Again human bodily organs become weak, it is very difficult for a man to save himself from this virus. Then it enters blood cell. Due to the lack of oxygen, the infected person will die. According to World Health Organization, $80 \%$ of infected persons should stay at home indeed [3].

\section{Impacts of Fatal Coronavirus on Massive Humanity}

According to Worldometers, COVID-19 coronavirus pandemic as of 17 April 2020, the total number of coronavirus cases was 2,219,314; the total number of death was 149,900 ; the total number of recovery was 560,975 ; whereas the mild condition was $1,451,936(96 \%)$; the critical condition was $56,503(4 \%)$; the recovery was $560,975(79 \%)$; and deaths were $149,900(21 \%)$. The United Nations declares a US\$2 billion coordinated global humanitarian response plan to fight against COVID-19 in the vulnerable countries. The UN aims to save millions of people in order that the virus can be prevented from circling back globally. The UN Secretary General António Guterres declares:

COVID-19 is menacing the whole of humanity - and so the whole of humanity must fight back. Individual country responses are not going to be enough. [...] We must come to the aid of the ultravulnerable - millions upon millions of people who are least able to protect themselves. This is a matter of basic human solidarity. It is also crucial for combating the virus. This is the moment to step up for the vulnerable. (United Nations Office for the Coordination of [4].

Moreover, Secretary General for Humanitarian Affairs and Emergency Relief Coordinator Mark Lowcock comments:

To leave the world's poorest and most vulnerable countries to their fate would be both cruel and unwise. If we leave coronavirus to spread freely in these places, we would be placing millions at high risk, whole regions will be tipped into chaos and the virus will have the opportunity to circle back around the globe [4].

In the year 2019-20, the global epidemic of novel coronavirus is referred to as a global outbreak of coronavirus (COVID-19), and the ongoing and rapid spread of its current event is getting increased in the 192 countries of the world. The disease is caused by a fatal virus. The virologists regard coronavirus as Acute Respiratory Syndrome Associated Coronavirus 2 or SARS-CoV-2. By the middle of the month of December 2019, the provincial capital of Hupei Province in China (the then $7^{\text {th }}$ largest city), the authority of Wuhan city has identified a novel type of coronavirus. At that time about 41 Chinese people were infected by the virus for which they had to suffer from severe lung inflammation or pneumonia. At first, no clear clue of their disease was identified nor could the patients be cured by conventional anti-virus treatments [21]. Coronavirus is believed to have infected the market sellers and buyers through the evolution of any animal sold out in the wholesale market of Huanan seafood in Wuhan city. Later, the Chinese scientists were able to identify this new type of coronavirus in Wuhan Science Laboratory, which is known as manmade virus.

A coronavirus infected person feels fever, chest pain, chills, feels rapid heartbreak, respires difficultly, coughs, sneezes, and symptoms of pneumonia will be felt. However, SARS coronavirus was first transmitted from animal to man, but now it has enabled to evolve from man to man [22]. Already in most of the countries of the world, the transmission of the virus has spread from person to person. The virus can remain dormant for 2-14 days after being infected in the body and can be infected with another person's body during incubation period. The disease is the result of the infection; the World Health Organization has deemed this disease as a novel coronavirus-19. The symptoms of the infection may include fever, dry cough, and shortness of breath, muscle aches and depression. The disorder can be complicated if it is not properly treated at the right time for which it can lead to inflammation of lungs, pneumonia, acute respiratory symptoms, acute immune response (sepsis) to antibacterial blood, and antibiotic shock (septic shock); and, eventually, death can happen. There was no preventive vaccine or effective preventive treatment for coronavirus disorder still now.

Though at first the spread of the virus was low, the rate of its infection began to increase rapidly and severely in the mid-January 2020[23]. According to data obtained by 13 March 2020, more than 1 lakh and 35 thousand people had been confirmed to be infected. The presence of the virus was confirmed in all provinces or administrative departments of provincial sectors in China. However, beyond the officially published numbers, many more people were infected with the virus, which was not identified. The presence of the virus was confirmed in 121 countries and administrative regions outside China. The first person died of coronavirus on January 9, 2020. And then, on

21 . The New York Times. (29 January 2020). "Is the World Ready for the Coronavirus?" An Editorial Report.

${ }^{22}$.CNBC. (24 January 2020). "China virus death toll rises to 41, more than 1,300 infected worldwide."

${ }^{23}$.Shih, Gerry; Lynch, David J.; Denyer, Simon. (27 January 2020). "Fifth coronavirus case confirmed in U.S., 1,000 more cases expected in China." The Washington Post. 
March 13, 2020, a total of 4990 people died. In addition, 70,395 people were possible to be recovered. The death toll from the SARS coronavirus-2 on February 10, 2020 exceeded the number of deaths. The overall death rate was $4.2 \%$ on 25 March 2020 .

Public health authorities are trying heart and soul to control the spread of SARS coronavirus-2. The government of each country has banned domestic international and international travel, imposed restrictions on going out of home and quarantine has been managed so that any coronavirus infected patient cannot get mixed with anybody. The daily life of about 17 crore people in China has been disrupted due to the deadliest disease.

On 30 January 2020, the World Health Organization has termed the pandemic outbreak of coronavirus and its epidemic as a Public Health Emergency of International Concern (PHEIC). The declaration is necessary for the vulnerable countries and regions where health care system is relatively weak, considering the pandemic outbreak when the virus spreads. Moreover, the necessary information on coronavirus-19, there has been a proliferation of false or false information, and even horror-provoking rumors in the news, on internet or social media, like Twitter, Facebook, and e-mail which is called the Worldwide Information Spread. ${ }^{24}$ In many countries of the world, the spread of foreign terrorism, especially of racism, misinformation about coronavirus and online conspiracy theories against the Chinese has increased across the globe[25].

A virologist Minal Dakhave Bhosale and her team design a Coronavirus Testing Kit namely Patho Detect. This testing kit is able to diagnose in two and a half- hours whereas the imported testing kits take 6-7 hours. The virologists have enabled to test the patients whether their coronavirus report is 'positive' or 'negative.'

Bhosale points out that Mylab Discovery situated in Pune becomes the first Indian firm to get full-approval to make and sell testing kits in India. It ships the first batch of 150 to diagnostic labs in Pune, Mumbai, Delhi, Goa and Bengaluru after discovery [5].

\section{Data Collection}

To collect data, the present researcher had to depend on the information and reports of the daily newspapers, critical comments made by doctors, health specialists, and reporters, internet sources, the Global News, Worldometers, World Health Organization,

24 https://www.technologyreview.com/s/615184/thecoronavirus-is-the-first-true-social-media-infodemic/

${ }^{25}$.The Global News. (3 February 2020). "Coronavirus fears trigger anti-China sentiment across the globe."
United Nations, United Nations Office for the Coordination of Humanitarian Affairs, BBC News, CNN News, BTV News, NPR News, and so on. He had to spend more than one month to carry out this potential research project maintaining home quarantine and social distancing along with family in Dhaka, Bangladesh. Since this terrifyingly coronavirus pandemic outbreak is now on the increase around the world, the right information is not feasible to highlight in this research project. The number of death toll, infection and recovery as of 16 April 2020 was taken from the World Health Organization and Worldometers.

\section{Data Analysis}

According to the reports of Worldometers as well as World Health Organization, data were collected dated as of 16 April 2020. Based on their information concerning novel coronavirus pandemic outbreak, it was feasible for the current researcher to show the number of death toll, infection, and recovery of the following countries. Unfortunately, the terrifyingly pandemic situation is getting happened around the world. This research-work will not guarantee when this pandemic outbreak will stop since no medical practitioner of scientist has discovered any medicine or vaccine yet.

Table-1.1: Coronavirus Seriously Infected Countries with reported laboratory-confirmed COVID-19 death toll Coronavirus disease 2019 (COVID-19) as of 16 April [26]

\begin{tabular}{|c|c|c|c|c|c|}
\hline $\begin{array}{l}\text { Reporting } \\
\text { Countries }\end{array}$ & $\begin{array}{l}\text { Total } \\
\text { Infected }\end{array}$ & $\begin{array}{l}\text { Total } \\
\text { New } \\
\text { Infected }\end{array}$ & $\begin{array}{l}\text { Total } \\
\text { Deaths }\end{array}$ & $\begin{array}{l}\text { Total } \\
\text { New } \\
\text { Deaths }\end{array}$ & $\begin{array}{l}\text { Total } \\
\text { Recovered }\end{array}$ \\
\hline Bangladesh & 1,572 & 341 & 60 & 10 & 49 \\
\hline USA & 677,570 & 29,567 & 34,617 & 2,174 & 57,508 \\
\hline UK & 103,093 & 4,617 & 13,729 & 861 & 0 \\
\hline France & 165,027 & 17,164 & 17,920 & 753 & 32,812 \\
\hline Italy & 168,941 & 3,786 & 22,170 & 525 & 40,164 \\
\hline Spain & 184,948 & 4,289 & 19,315 & 503 & 74,797 \\
\hline Belgium & 34,809 & 1,236 & 4,857 & 417 & 7,562 \\
\hline Netherlands & 29,214 & 1,061 & 3,315 & 181 & 250 \\
\hline Germany & 137,698 & 2,945 & 4,052 & 248 & 77,000 \\
\hline Iran & 77,995 & 1,606 & 4,869 & 92 & 52,229 \\
\hline China & 82,341 & 46 & 3,342 & 0 & 77,892 \\
\hline India & 13,430 & 1,060 & 448 & 26 & 1,768 \\
\hline Total & $1,676,638$ & 67,718 & 128694 & 5790 & 422,031 \\
\hline
\end{tabular}

If we look at the table, we can understand about the exact numbers of infection, death toll and recovery of severely infected-countries whereas the overall infection was $1,676,638$; the overall death was 128694; and the overall recovery was 422,031 .

From this table, it is seen that mostly infected countries of the world were USA $(677,570)$, Spain $(184,948)$, Italy $(168,941)$, France $(165,027)$, Germany $(137,698)$ and UK $(103,093)$, whereas the death toll of these countries were USA $(34,617)$, Spain $(19,315)$, Italy $(22,170)$, France $(17,920)$, Germany $(4,052)$ and UK (13,729) dated as of 16 April 2020. On the contrary, the overall recovery of these countries was

26 . https://www.worldometers.info/coronavirus/ 
Germany (77,000), China (77,892), Spain $(74,797)$, Italy $(40,164)$, USA $(57,508)$, and Iran $(52,229)$.

This table also shows that there was no death in China as of 16 April 2020. Bangladesh (10), India (26) and Iran (92) numbers of coronavirus infectedpatients died. Though the number of death was the least in Bangladesh as shown in the chart, this research was conducted. In fact, still now the coronavirus pandemic outbreak is on the increase around the world. It is reported that the number of infection, death and recovery may increase and decrease in any countries of the world any time. There is no certainty of this pandemic outbreak while the infection or affection of this fatal virus will be completely prevented.

Table-1.2: The Number of Infected Countries

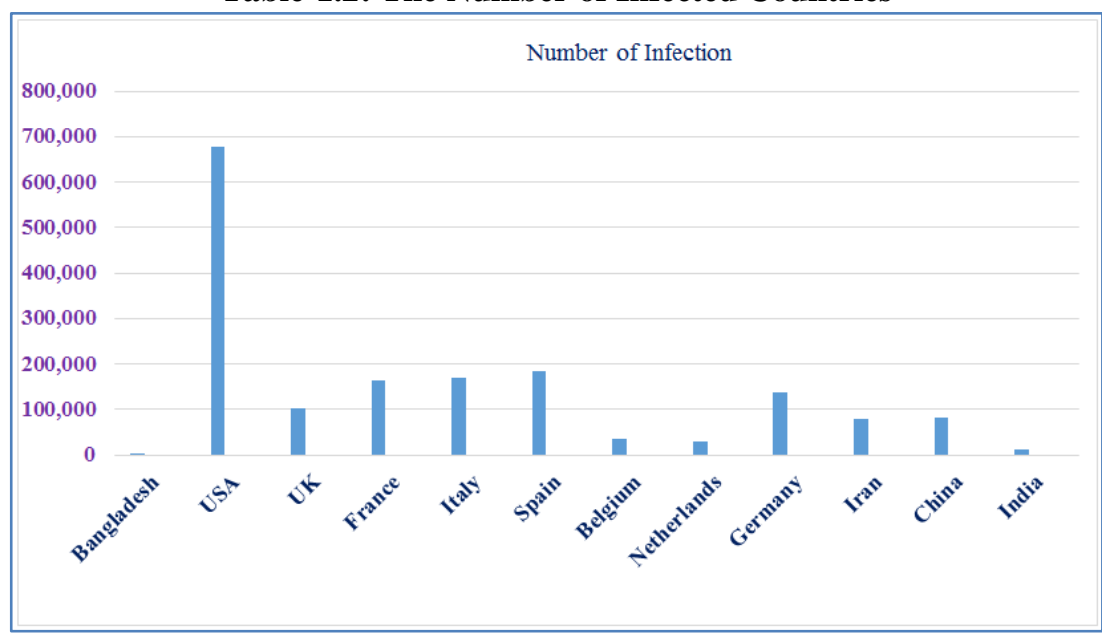

From this table it is seen that in Bangladesh $(1,572)$, USA $(677,570)$, UK $(103,093)$, France $(165,027)$, Italy $(168,941)$, Spain $(184,948)$, Belgium $(34,809)$, Netherlands $(29,214)$, Germany $(137,698)$,
Iran (77,995), China (82,341), and India $(13,430)$ numbers of people were infected by novel coronavirus. USA, Spain, France, Italy, UK and Germany surpassed other countries in terms of overall infection.

Table-1.3: The Number of Deaths

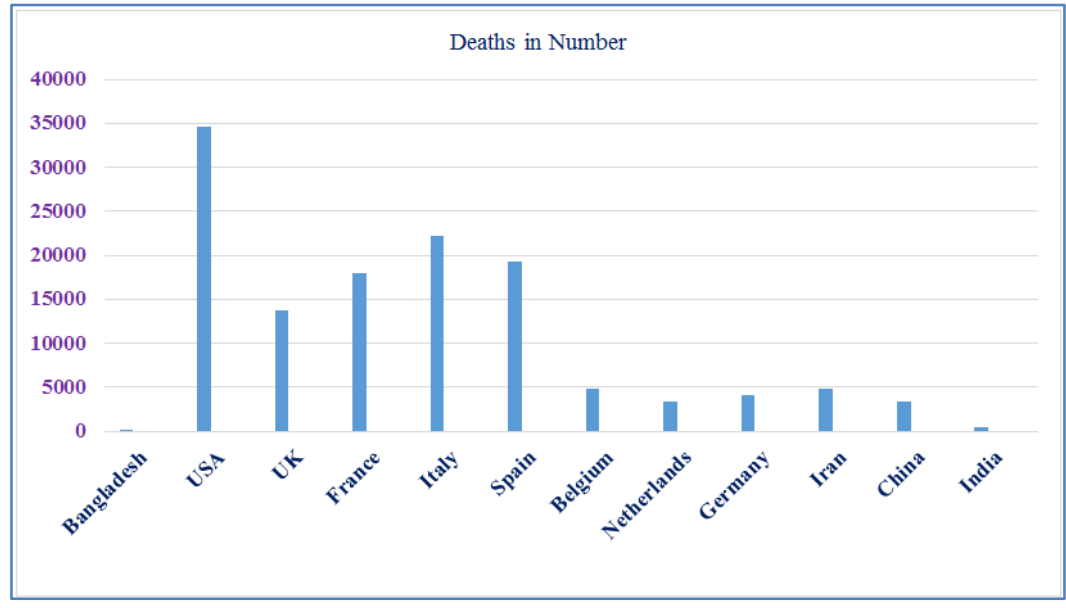

From this chart it is seen that in Bangladesh (60), USA $(34,617)$, UK (13,729), France $(17,920)$, Italy (22,170), Spain (19,315), Belgium (4,857), Netherlands $(3,315)$, Germany $(4,052)$, Iran $(4,869)$,
China (3,342), and India (448) people died of novel coronavirus. USA, Italy. Spain, France, Italy, and UK surpassed other countries in terms of the overall death toll. 


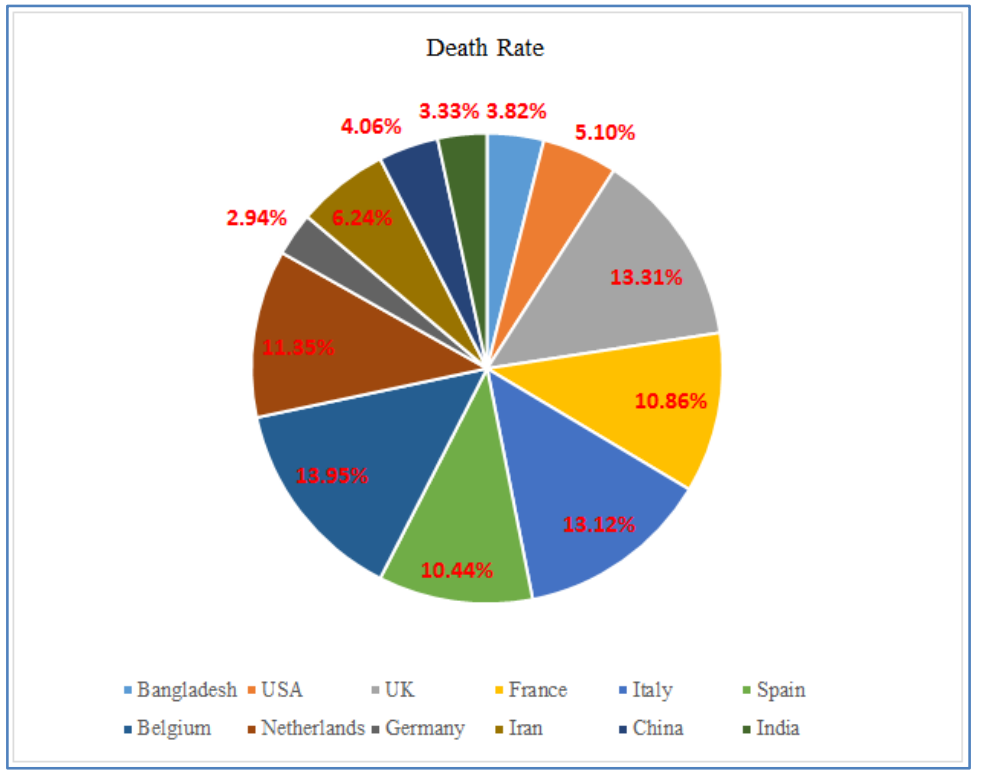

Graph-1: Death Rate

This pie chart shows the results of date rate of the severely infected countries by novel coronavirus- 19 . Now it highlights the death rate of the infected countries where $1,676,638$ people were infected totally: In Bangladesh, 1,572 people were infected on 16 April 2020 from which $3.82 \%$ of patients died due to the fatal virus. Similarly, In USA (5.10\%) from 677,570; UK
(13.31\%) from 103,093; France $(10.86 \%)$ from 165,027 ; Italy $(13.12 \%)$ from 168,941 ; Spain $(10.44 \%)$ from 184,948; Belgium (13.95\%) from 34,809; Netherlands (11.35\%) from 29,214; Germany (2.94\%) from 137,698; Iran (6.24\%) from 77,995; China $(4.06 \%)$ from 82,341 ; and India (3.33\%) from 13,430 patients died.

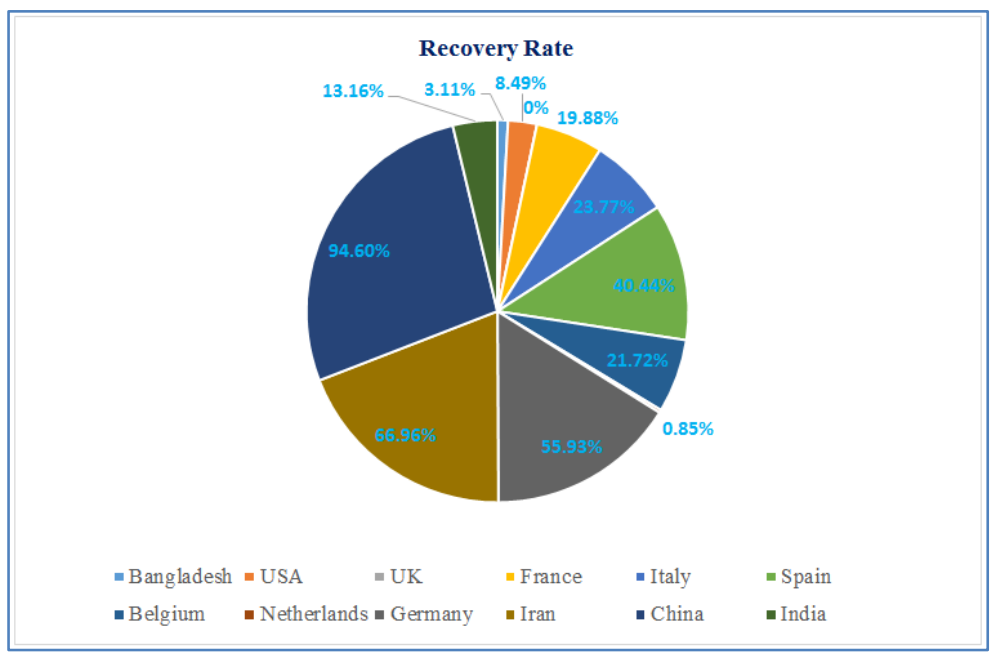

Graph-2: Recovery Rate

This pie chart fosters the results of recovery rate of the severely infected countries by COVID-19. Now it would like to focus on the recovery rate of the infected countries where 422,031 people came round totally: In Bangladesh, 49 people got rid of coronavirus as of 16 April 2020 from which $3.11 \%$ of patients got recovered from the novel coronavirus. Similarly, In USA $(8.49 \%)$ from 57,508; UK $(0 \%)$ from $0 \%$; France (19.88\%) from 32,812; Italy $(23.77 \%)$ from 40,164; Spain (40.44\%) from 74,797; Belgium (21.72\%) from 7,562; Netherlands (0.85\%) from 250; Germany $(55.93 \%)$ from 77,000 ; Iran $(66.96 \%)$ from 52,229;
China (94.60\%) from 77,892; and India (13.16\%) from 1,768 patients came round.

\section{Novel Coronavirus (2019-nCOV) Preventive Measures}

According to $\mathrm{UN}$, WHO, medical scientists and health specialists, there are some most important measurements which are mentioned below with a view to preventing coronavirus disease-2019 and coronavirus infection. It is important to note here the fact that coronavirus spreads from man to man in the two major ways. The first process of coronavirus infection is found to happen in the two steps. The first step is that if 
any coronavirus-infected man goes out of his room and sneezes without covering his mouth, the virus can float in the air for several hours (within a range of 1-2 meters). The second step is that if coronavirus breathes in the air of the spleen, it can enter into other people's lungs through throttle or airway. The second process of coronavirus infection also occurs in several steps. First Step: If the coronavirus-infected person does not follow the rules of cough etiquette, his hands will be affected by coronavirus. Second Step: If any coronavirus infected person touches the surface of any object in his surroundings with his hands, the virus may remain on that surface for several days. Third Step: If any infected person touches the surface of any things, the new person will be infected by coronavirus. Fourth Step: Coronavirus cannot be infected within the body or lungs when any hands touch. So, if any newly coronavirus inflected person touches nose, mouth or eyes with hands, the virus will enter his body through the open bile of those areas and begin to spread in the neck first and, then, in the lungs. If coronavirus is prevented at the beginning of the two processes, or at an early stage, it can be possible to successfully prevent the transmission of this virus and disease.

According to United Nations Medical Directors (28 January 2020), there is no specific treatment for this infected disease caused by COVID19. Symptoms can be identified based on the patient's clinical condition. Supportive care for an infected patient can be fruitful. Since still now no scientist has enabled to discover vaccine or medicine, it is indispensable for us all to abide by the following suggestions very strictly:

\section{To Maintain Social Distancing}

Coronavirus can exist in any human body unknowingly for more than two weeks without any symptoms. If any coronavirus infected person sneezes or coughs, the virus aqueous particles begin to float at a distance of 3 to 6 feet in the surrounding air and it can enter human body through normal breathing within that range. Because of this, if there is much public outcry outside, such areas should be avoided and nobody can walk out without any urgent need so that possible coronavirus particles floating in the air cannot enter human body through breathing.

\section{To Disinfect Hand Wash}

Coronavirus can be found in various objects in the ecology. So, if any man touches those things with his hands, he can be infected. It is found in the medical scientific research that the virus can last for an average of 4 to 5 days on the surface of wood, plastic or metal objects. People have to touch them with their hands every single day in terms of livelihood and necessity. Therefore, it is very important to wash hands thoroughly after touching any objects. The following norms are very essential to pay special attention to the risky areas of touch.
- Any person's personal objects that are frequently touched by hands, such as mobile phones, laptops, etc.

- Touching devices that many people touch, for example, ATM machines, including cash payment instruments and other devices, such as laptops, computer monitors at a store, or other location, keys, keyboards, handles, etc.

- Touch any furniture, such as chairs, tables, etc.

- Touch the door handle of any room or vehicle.

- Touch any paper money, bank debit or credit card, etc. where they are kept, such as wallet or purse.

- Touch any dishes or bottles of the restaurant or any other food store. It is not possible to be completely sure whether these dishes are touched by many people and whether they have been properly disinfected.

- Wipe hand towels or handkerchiefs that are touched daily.

- To shake hands, or to get in close contact with anyone on the street or somewhere outside home.

In the above lists, it is necessary to be careful after touching hands, or disinfecting hands as soon as possible. The following hand washing procedures should be followed strictly:

- First to wet hands properly in clear water. After that special disinfectant soap (if not common soap is available) should be applied in the hand and rub the whole hand with soap's foam.

- It is necessary to make sure that every finger in the hand is soapy so that the finger of one hand can be crushed by inserting the finger of the other hand into the gap.

- To make sure to rub the old fingers of the two hands with soap.

- To rub the palm of one hand and then the palm of the other hand and after then, the back of the palm of the other hand with the palm of one hand should be rubbed.

- Every nail needs to be cleaned very well.

- After opening the wearable objects, such as watch, ring on any other hand, the surface underneath objects must be cleaned.

- Rub hands with foam for at least 20-30 seconds thoroughly.

- Hands should be kept in containers, not in standing water, but after washing hands very well, hands should be completely free of soap.

- After washing hand, have to dry hands with one time used paper made handkerchief but not with a towel or handkerchief, because research shows that the virus causes 100 times more virulence in the wet hands. Hand will not be dried with the towels used by more than one person, and hands will not be repeatedly dried with the same towels. Therefore, no towel or 
handkerchief other than the one time used paper made handkerchief should be used.

- Hold the dry paper made handkerchief; close the water faucet; and, then, open the door of the toilet. Virus can spread at the door handle of water taps and toilets. Then, handkerchief should be poured into a lid waste container.

- Since it is necessary to wash hands several times in a day, it is better to use soft soap for the skin. If there is no soap or water, wash hand with a sterile disinfectant with $60 \%$ of alcohol. Filthy hands need to be washed with soap and water as per rules of health.

When hands will be washed, the following instructions are very necessary:

- Wash hands after coughing or sneezing;

- Any public gatherings or places that include public transportation, markets or places of worship; after visiting them, wash your hands.

- Wash hands after reaching at work place from home.

- Wash hands after reaching home from work.

- Wash hands after touching the surface of any object.

- Wash hands before or after serving any patient.

- Wash hands before and after taking a meal.

- Wash hands after drainage.

- Wash hands after touching the waste.

- Wash hands after touching pets or any other domestic animal.

- Wash hand after touching babies' diapers.

- If any hands look dirty, wash them immediately.

- Coronavirus cannot be transmitted from one patient to another or to any other person in the hospital or health care center; that is why all health workers serving there must wash their hands and disinfect them in the following moments: Before touching the patient; before applying the cleansing or disinfection method; immediately after the patient has the possibility of falling the juice or fluid on the body; after touching the patient; touching the environment around the patient.

\section{Surety of Disintegration Process after Washing Hands}

- Sufficient paper made handkerchiefs or tissue paper can be arranged to cover mouth or to dry wet hands in some places, like restaurants, tea and coffee shops, grocery, medicine shops, markets, or shopping malls, etc. Wash hands in the sanitizer or foam. A lid waste bin or bin may be arranged to remove the paper made handkerchief after use.

- While traveling or staying outside home, always carry hand sanitizer with bottle and handkerchief or tissue paper.
Do not touch Nose, Mouth and Eyes with Hands

Coronavirus generally infects human body through nose, mouth, eyes and open bile. Therefore, no nose, mouth, or eyes can be touched in the hands of an infected virus. If it is necessary to touch nose by hands, wash hands and disinfect them. Use paper's handkerchief for touching nose, mouth and eyes. For this reason, it is important to always confirm the presence of soap-water either alcohol-based disinfectant or paper made handkerchief in hands. To touch nose, mouth and eyes by hand is a very common phenomenon. Almost all of them do it without any reason since it is a long habit. It has been shown in the research that people touch different parts of their mouth by hands more than 20-times per hour. Many suffer from emotional stress, deep thoughts, for some unknown mental depression. Touch nose, mouth, and eyes by hands for itching. So, first of all, each person has to follow self-observation regularly for some time; at what time or for what reason a man touches nose, eyes or mouth by his hands. After identifying the causes and becoming aware of them, try to keep aloof from such regular habits. The limit of touching nose, mouth, and eyes by hands should be minimized to the highest extent.

\section{Net and Clean Environment}

- Things that many exotic people touch at home and office, such as door handles, computer, keyboards and monitor screens, laptop, mobile phone, or any other widely used furniture, etc. should be regularly cleaned through disinfectant spray or fluidity.

- After coming home, wearable cloths and other commonly used clothing, such as bed, etc. should be washed regularly.

\section{Further Suggestions for Coronavirus Infected Patients}

- A minimum distance of 3-6 feet should be maintained from the person who suffer from fever, cold, cough, and sneezing so that the virus particles floating in the air do not enter the body through inhalation.

- Don't spit on the road and everywhere, because the virus can spread from the spit.

- The person who cough or sneeze must cover nose and mouth with temporary handkerchief or tissue paper; and that paper should be dumped in the waste immediately. Cough and sneezing cannot be covered with empty hands since dirty germs spread in the hands. If there is no handkerchief, cover the face with the folds of the elbow or the upper part of the cloth. If symptoms are found in any familiar person, he must contact a health center or emergency phone immediately so that he can be tested quickly and quarantined or isolated if needed.

- Avoid eating prepared and served food in an unhealthy environment on the road or elsewhere, virus can spread through food in 
unhealthy environment or through dirty dishes, pots, plates, or glasses.

- The exposure to open wastes falling on the sidewalk or medical waste falling in the hospitals and elsewhere should be avoided.

- Health workers working in the hospitals and other health centers must wear special medical masks, PPE, and gloves so that virus cannot transmit from one man to another.

According to United Nations Medical Directors [4], protect from illness with respiratory pathogens by practicing hand and respiratory hygiene and safe food practices:

- Clean hands by using alcohol-based hand rub for 20-30 seconds when hands are not visibly soiled or soap and water for 40-60 seconds;

- While coughing and sneezing, cover mouth and nose with elbow or tissue and after then, throw tissue away in a closed bin and then wash hands;

- Maintain hand hygiene while contacting with respiratory secretions and dirty things.

- In areas experiencing cases of coronavirus, try to avoid direct unprotected contact with animals and surfaces in contact with animals;

- Avoid the consumption of raw or undercooked animal products. Raw meat, milk or animal organs need to be handled with care; avoid cross-contamination with uncooked foods;

- Keep a daily temperature log during duty travel to monitor health and symptoms for two weeks after returning.

According to medical science, quarantine, home quarantine, social distancing and lockdown can play important role to prevent novel coronavirus. Therefore, we must follow rules of health as well as quarantine hygiene very strictly to keep a healthier and happier life. According to Human Immunodeficiency Virus [6], several types of precautionary means are being taken to prevent from novel coronavirus-19 so that we can keep neat and clean environment, maintain social distancing from returning overseas, infected persons, or avoid public gatherings. In fact, the words, Isolation, Quarantine, and Home Quarantine have come to us to protect from the coronavirus infected persons.

According to Mamun [7], the word 'Quarantine' means segregation. One is isolated from others. In this system, a healthy man is separated from the patient or the suspected person. Mamun also points out that virus are highly contagious and infected due to its extreme mutant. An infected person can infect 3-5 persons. Later, those infected persons can infect 10-15 healthy men. Thus from a focus patient, this virus in terms of geometrical progression can infect many healthy men. A focus patient can give birth a lot of patients which is gradually on the increase. If we can separate the infected person through quarantine process, this transmission chain can be broken. Otherwise, the pool of an infected person will be on the increase in terms of geometrical rate. Without implementing quarantine policy at the primary stage, the infected and contagious persons will be on the increase at an alarming rate around the world.

\section{Quarantine}

According BBC and NPR [8], Quarantine is compulsory for those who have already been infected by coronavirus. They will stay at home. Nobody will come in contact with them. One who will get mixed with the infected person, must abide by precautionary steps. If he wants to go to hospital, he must inform the authority. Those will take charge of the patient, the authority must be informed. Precautionary steps, rules and regulations must be followed strictly. Suppose: "You were on a board, where there was also a coronavirus infected patient with you. In that case, the authority may order you to remain in quarantine or isolation. For instance, those who came from Wuhan, China, were kept in quarantine for 14 days."

\section{Home Quarantine}

According to Mamun [7], Home Quarantine means following the quarantine rules at staying home. It means that every member of the family will follow the personal quarantine hygiene staying at home. In this system, it is possible to bring every person of the country under quarantine. Its main purpose is that each member of each family will follow quarantine hygiene separately in the domestic environment enjoying with ease, food and convenience. Those who are sick, old, suspected person or returning overseas quarantine must be done in a separate room. If anybody is sick, he may take medical treatment. He may get admitted into institutional care in terms of necessity. Most people of the society can be involved and familial comfort can be provided in the domestic environment. Home quarantine demands acceptance as a very effective step.

\section{Duration of Quarantine}

The duration of personal quarantine is 14-21 days when the symptoms of coronavirus are noticed. The reason is that the host immune defence mechanism of the body can destroy the virus after it enters human body. Then the virus becomes inactive. The virus is not likely to infect other man.

\section{Social Distancing}

According BBC and NPR [8], Social Distancing means that nobody will not go out without any special purpose. He will have to remain at home. He may go out for any emergent or serious reasons, like, to buy food or medicine. He must abide by the rules of health and must wash hands with soap after each 20-30 minutes; he must refrain himself from the crowded places, getting in the public transport, travelling, going to cinema-theatre, even mosque or 
temple. He must maintain 6-feet social distancing from others. He will not get mixed with friends and vice versa.

\section{Lockdown}

According BBC and NPR [8], Lockdown is not a system of health authority. It is an administrative, legal or government system. It also means that airline is closed, borders are closed, and movement is banned. It is the decision of the authorities, but not the decision of the self-motivated decision of the citizen. Whatever the authorities say, citizens will have to follows the rules of health strictly.

\section{Conclusion}

Global population is facing a dire situation due to the pandemic outbreak of new coronavirus. Each and every day many men and women die prematurely around the world though global leaders, doctors and scientists are trying heart and soul how this pandemic outbreak can be controlled. For this purpose, this research paper has been conducted to investigate the impacts of pandemic outbreak of novel coronavirus on massive humanity. Origination, history, outbreak, and reaction of fatal coronavirus have been discussed in this study. Symptoms and diagnosis of coronavirus have also been exposed here. How coronavirus breaks lineage out in human body; how it attacks lungs and alveoli seriously; and how a shortage of oxygen is found in the body has been properly discussed. For data collection, this study has taken materials from global daily newspapers, internet sources, the Global News, Worldometers, World Health Organization, United Nations, United Nations Office for the Coordination of Humanitarian Affairs, BBC News, CNN News, BTV News, and NPR News. Thus this study has enabled to focus on the current impacts of new coronavirus on the vast majority of population. The overall infection, death and recovery have been fostered depending on the reports of WHO and Worldometers. This study has also highlighted the novel coronavirus (2019-nCOV) preventive measures to create awareness among the nations of the world. Finally, this study has emphasized upon quarantine, isolation, home quarantine, lockdown and social distancing.

\section{REFERENCE}

1. The Pratham Alo. "The name of disease is COVID19 emerging from Coronavirus." Online Desk, 12 February 2020.

2. Frias, Lauren. "A Wuhan seafood vendor believed to be one of the first coronavirus patients says 'a lot fewer people would have died' if the Chinese government acted sooner;2020.’https://www.yahoo.com/news/wuhan -seafood-vendor-believed-one-051432500.html

3. Ferdous, Sayrin. "What Happens after Coronavirus Enters Human Body." The Bangladesh Pratidin, column; 2020 1, 7.

4. Lowcock Mark. "UN issues $\$ 2$ billion appeal to combat COVID-19." United Nations Office for the Coordination of Humanitarian Affairs.2020; https://www.unocha.org/story/un-issues-2-billionappeal-combat-covid-19

5. Pandey, Geeta. "Coronavirus: The woman behind India's first testing kit," BBC News, Delhi, India; 2020. https://www.yahoo.com/news/coronaviruswoman-behind-indias-first-000609807.html

6. Human Immunodeficiency Virus. "What is Isolation, Quarantine and Home Quarantine and when do we obey them?" Bangla New; 2020. https://www.banglanews24.com/health/news/bd/77 7939.details

7. Mamun, Doc. Md. Ayub Al. "What is Quarantine and the Why?" The Dainik Jugantor. Hepatolgy Department, Bangabandhu Sheikh Mujib Medical University, Dhaka; 2020. https://www.jugantor.com/todayspaper/features/stay-well/295572/কোয়ারেন্টিন-কী-ওকেন (What is Quarantine and the Why?)

8. BBC \& NPR. "Quarantine, Isolation, Social Distancing, and Lockdown: What are they?" The Pratham Alo. 2020; https://www.prothomalo.com/life-style/article/1646635 